\title{
Neural Network-Based Approach for Identification of the Harmonic Content of a Nonlinear Load in a Single-Phase System
}

\author{
C. F. Nascimento, A. A. Oliveira Jr, A. Goedtel, I. N. Silva, Member, IEEE, and P. J. A. Serni
}

\begin{abstract}
In this paper an alternative method based on artificial neural networks is presented to determine harmonic components in the load current of a single-phase electric power system with nonlinear loads, whose parameters can vary so much in reason of the loads characteristic behaviors as because of the human intervention. The first six components in the load current are determined using the information contained in the time-varying waveforms. The effectiveness of this method is verified by using it in a single-phase active power filter with selective compensation of the current drained by an AC controller. The proposed method is compared with the fast Fourier transform.
\end{abstract}

Keywords - Harmonics, power system, artificial neural networks

\section{INTRODUÇÃO}

$\mathrm{O}$ CRESCENTE uso de equipamentos baseados na eletrônica de potência destaca a importância da relação entre esta área da engenharia elétrica e a qualidade da energia elétrica [1], [2]. Mesmo proporcionando um controle eficiente do fluxo de energia, estas cargas produzem correntes harmônicas que acarretam o proporcional aumento das perturbações em sistemas elétricos, as quais causam a piora da qualidade de energia elétrica. Em sistemas monofásicos, a poluição harmônica gerada pelas cargas não-lineares individualmente é de pequena potência, porém, quando usadas em grande quantidade em sistemas elétricos podem causar problemas significativos de distorção. A poluição, portanto, não está restrita somente aos ambientes industriais, mas também está presente em ambientes residenciais e comerciais. Ademais, o fluxo de corrente não-linear pelo sistema resulta em uma série de efeitos indesejáveis [3], [4].

Os problemas relacionados com a distorção podem ser resolvidos utilizando-se de filtros com o objetivo de cancelar os componentes harmônicos do sistema [5]-[9]. Dentre as diversas configurações possíveis para a realização de um

Os autores agradecem ao $\mathrm{CNPq}$ pelo apoio financeiro (Processo 142128/2005-8, Processo 142326/2005-4, Processo 474290/2008-5).

C. F. Nascimento é professor do Centro de Engenharia da UFABC, Santo André, SP, Brasil, claudionor.nascimento@ufabc.edu.br.

A. A. Oliveira Jr é professor do Departamento de Engenharia Elétrica da USP, São Carlos, SP, Brasil, azauri@sc.usp.br.

A. Goedtel é professor do Departamento de Eletrotécnica da UTFPR-CP, Cornélio Procópio, PR, Brasil, agoedtel@utfpr.edu.br.

I. N. Silva é professor do Departamento de Engenharia Elétrica da USP, São Carlos, SP, Brasil, insilva@sc.usp.br.

P. J. A. Serni é professor do Departamento de Engenharia Elétrica da UNESP-FEB, Bauru, SP, Brasil, paulojas@feb.unesp.br.
Filtro Ativo de Potência (FAP), a topologia denominada Filtro Ativo de Potência Paralelo (FAPP) é a mais empregada atualmente. Sua configuração é constituída de um inversor do tipo fonte de tensão, conectado em paralelo com a carga [3]. Sua função é injetar uma corrente apropriada no Ponto de Acoplamento Comum (PAC) do sistema, a qual cancela os componentes harmônicos da corrente drenada da fonte de tensão [10]. As características de compensação de um FAPP são definidas, principalmente, pela estratégia usada para determinar o conteúdo harmônico da corrente de carga e para criar a corrente de referência do seu sistema de controle [6].

A determinação desta corrente de referência tem sido feita através de duas abordagens: a chamada abordagem no domínio do tempo [11], [12], e a abordagem no domínio da freqüência [7], [8]. No domínio da freqüência, a Transformada Discreta de Fourier (DFT - Discrete Fourier Transform) é uma técnica tradicional e precisa, muito utilizada na análise espectral da corrente de carga [13], [14].

Ela é empregada de forma online com o auxílio do algoritmo da Transformada Rápida de Fourier (FFT - Fast Fourier Transform), que identifica os coeficientes da DFT de forma mais eficiente e possibilita a reconstrução do sinal discretizado, o qual pode ser usado como corrente de referência [14]. A FFT, por ser um método consagrado e muito utilizado na identificação de conteúdo harmônico, é empregada para propósitos de comparação com técnicas alternativas de identificação de conteúdo harmônico [7], [8]. A FFT truncada também tem sido usada com o intuito de reduzir o esforço computacional inerente a ela [14].

Um Sistema Inteligente (SI) pode ser usado no processo de estimativa do conteúdo harmônico do sinal de corrente como uma ferramenta alternativa à FFT [15]. Dentre os SIs mais utilizados está a Rede Neural Artificial (RNA) [16]-[21]. A RNA é treinada de forma offline, e utiliza os dados de treinamento levantados a partir da simulação de cargas nãolineares. Tais simulações formam o conjunto de dados de treinamento e de teste da abordagem neural. Após o processo de treinamento e validação, a RNA identifica de forma online cada componente harmônico a partir das amplitudes da corrente de carga amostradas.

Neste trabalho propõe-se um método baseado em RNA para determinar a amplitude de cada um dos seis primeiros componentes harmônicos da corrente de carga de um sistema monofásico. A determinação dos componentes realiza-se em um semiciclo do ciclo da tensão de alimentação. $\mathrm{O}$ método proposto é comparado ao algoritmo da FFT truncada para se 
verificar a sua eficácia. A carga não-linear usada é composta de um controlador CA monofásico, que alimenta um conjunto de três lâmpadas incandescentes de $100 \mathrm{~W}$ cada uma, constituindo um regulador de intensidade luminosa dessas lâmpadas (dimmer), conforme mostrado na Fig. 1 [4]. Esta carga foi escolhida para testar o método proposto devido às características dos componentes harmônicos da sua forma de onda de corrente. Conforme se observa em [4], estes componentes harmônicos podem variar seja pela interferência humana na regulação do nível de intensidade luminosa de um ambiente, seja pela alteração da temperatura dos filamentos das próprias lâmpadas ou mesmo por fatores não previsíveis, tais como a queima de lâmpadas, substituição de lâmpadas com características de potência distintas daquelas consideradas no modelo original, entre outros.

Um FAPP simulado é apresentado neste trabalho de forma a validar a abordagem proposta e sua aplicabilidade em sistemas monofásicos.

E para tanto, a organização deste artigo segue a seguinte ordem: na Seção 2 serão apresentadas as características da carga e os aspectos do sistema estudado; na Seção 3 serão relatados os princípios envolvidos com a abordagem neural; na Seção 4, o método baseado na RNA é comparado ao método que utiliza a FFT truncada; e na Seção 5, os resultados de simulação do filtro. Finalmente, na Seção 6 , estão as conclusões.

\section{CORRENTE HARMÔNICA DO SISTEMA}

O controlador CA, apresentado na Fig. 1, representa uma carga não-linear para a fonte de tensão puramente senoidal $\left(v_{s}(t)\right)$. Ela é formada por uma chave semicondutora (TRIAC $A$ ), um circuito de disparo e um conjunto de lâmpadas incandescentes que possuem um comportamento resistivo (carga $R$ ). As amplitudes e fases dos componentes harmônicos desse sistema variam tanto com o ângulo de disparo do TRIAC quanto com a resistência $R$ do conjunto de lâmpadas, a qual varia conforme a temperatura. A Fig. 2 apresenta a tensão $\left(v_{L}(t)\right)$ aplicada à carga $R$ do controlador CA para um ângulo ajustado de disparo de $90^{\circ}$.

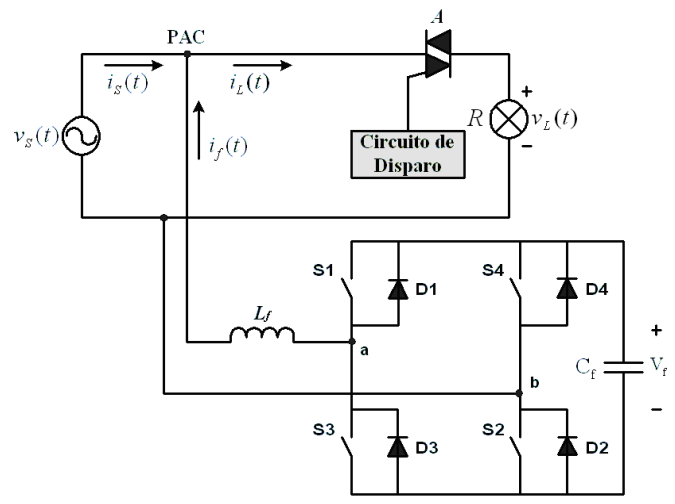

Figura 1. Sistema com um FAPP e um controlador CA.

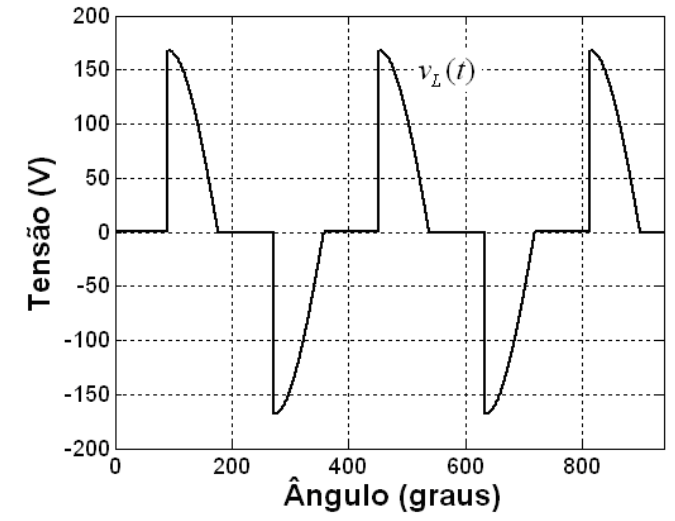

Figura 2. Forma de onda da tensão aplicada às lâmpadas.

A série de Fourier da tensão aplicada à resistência pode ser descrita como:

$$
\begin{aligned}
v_{L}(t)= & \frac{V}{\pi}\left\{\frac{1}{2}[\cos 2 \alpha-1] \cos \omega t+\frac{1}{2}[\operatorname{sen} 2 \alpha+2 \pi-2 \alpha] \operatorname{sen} \omega t\right. \\
& +\sum_{n=3}^{\infty}\left[\frac{\cos (n+1) \alpha-\cos (n+1) \pi}{n+1}\right. \\
& \left.-\frac{\cos (n-1) \alpha-\cos (n-1) \pi}{n-1}\right] \cos n \omega t \\
& \left.+\sum_{n=3}^{\infty}\left[\frac{\operatorname{sen}(n+1) \alpha}{n+1}-\frac{\operatorname{sen}(n-1) \alpha}{n-1}\right] \operatorname{senn} \omega t\right\}
\end{aligned}
$$

Onde:

$\alpha$ é o ângulo de disparo do TRIAC $A$;

$n$ é o $n$-ésimo harmônico ( $n$ ímpar);

$V$ é a tensão de pico da fonte.

A representação da corrente de carga $i_{L}(t)$ é obtida usandose a tensão $v_{L}(t)$ aplicada à resistência $R$, ou seja:

$$
i_{L}(t)=\frac{v_{L}(t)}{R}
$$

A resistência das lâmpadas varia com a temperatura e, conseqüentemente, com a tensão eficaz (RMS), que por sua vez varia com o ângulo de disparo do TRIAC, conforme (3) [4]. A Fig. 3 apresenta o comportamento da tensão RMS e da resistência das lâmpadas em função do ângulo de disparo $\alpha$ do TRIAC. A tensão RMS também pode ser determinada de forma aproximada através dos harmônicos de tensão da carga, expressa em (4).

$$
\begin{gathered}
V_{R M S}=V \sqrt{\frac{1}{2}-\frac{\alpha}{2 \pi}+\frac{\operatorname{sen} 2 \alpha}{4 \pi}} \\
V_{R M S}=\sqrt{\sum_{n=1}^{N} \frac{V_{n}^{2}}{2}}
\end{gathered}
$$

onde:

$V_{n}$ é o $n$-ésimo harmônico de tensão;

$N$ é o número de harmônicos.

A amplitude do $n$-ésimo componente harmônico de corrente $\left(I_{n}\right)$ é dada por:

$$
I_{n}=\frac{V_{n}}{R}
$$

A Fig. 4 mostra a variação não-linear da corrente RMS $\left(I_{R M S}\right)$ da carga que pode ser calculada por (6) ou aproximadamente por (7). 


$$
\begin{gathered}
I_{R M S}=\frac{V_{R M S}}{R}=\frac{V}{R} \sqrt{\frac{1}{2}-\frac{\alpha}{2 \pi}+\frac{\operatorname{sen} 2 \alpha}{4 \pi}} \\
I_{R M S}=\frac{V_{R M S}}{R}=\sqrt{\sum_{n=1}^{N} \frac{I_{n}^{2}}{2}}
\end{gathered}
$$

A Distorção Harmônica Total (THD - Total Harmonic Distortion) da corrente é dada por (8) [22]. A equação (9) apresenta a influência da distorção harmônica sobre a corrente RMS da carga, onde $I_{1}$ é o componente fundamental de corrente.

$$
\begin{gathered}
T H D=\frac{\sqrt{\sum_{n=2}^{\infty} I_{n}^{2}}}{I_{1}} \\
I_{R M S}=\frac{I_{1}}{\sqrt{2}} \sqrt{1+T H D^{2}}
\end{gathered}
$$

A Fig. 4 também ilustra a variação da $T H D$ de corrente em função do ângulo de disparo do controlador CA. Note que para valores abaixo de $100^{\circ}$, a $T H D$ tem uma variação que se aproxima da linear, mas a partir deste valor aumenta exponencialmente. As amplitudes dos harmônicos acima de $160^{\circ}$ causam uma alta $T H D$, mas elas são de baixa intensidade, como pode ser observado nas amplitudes da Fig. 5.

A potência reativa gerada pela corrente de carga não-linear causa o fator de deslocamento $(F D)$ do sistema, conforme (10), o qual leva em consideração os ângulos de fase da tensão $\left(\theta_{\mathrm{V}}\right)$ e da corrente fundamental $\left(\theta_{1}\right)$. O controlador CA representa uma carga reativa indutiva para o sistema, pois $\theta_{1}$ é atrasado em relação ao ângulo $\theta_{\mathrm{V}}$ para $\alpha>0$. Já a distorção harmônica, quantificada pela $T H D$, é responsável pelo fator de distorção (FDist) do sistema representada em (11). Sendo assim, tanto o $F D$ como o FDist modificam o fator de potência $(F P)$ do sistema que pode ser calculado utilizando-se de (12) para $\theta_{\mathrm{V}}=0$.

$$
\begin{gathered}
F D=\cos \phi_{1}=\cos \left(\theta_{\mathrm{v}}-\theta_{1}\right) \\
F D i s t=\frac{1}{\sqrt{1+(T H D)^{2}}} \\
F P=\frac{1}{\sqrt{1+(T H D)^{2}}} \cos \theta_{1}
\end{gathered}
$$

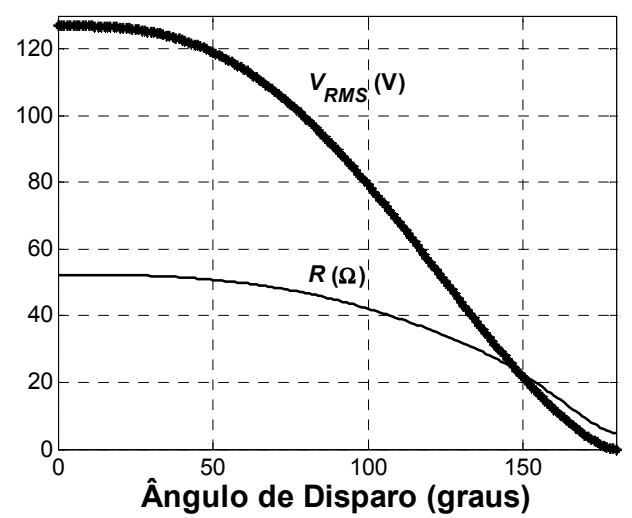

Figura 3. Variação da tensão RMS e de $R$ com o ângulo de disparo.

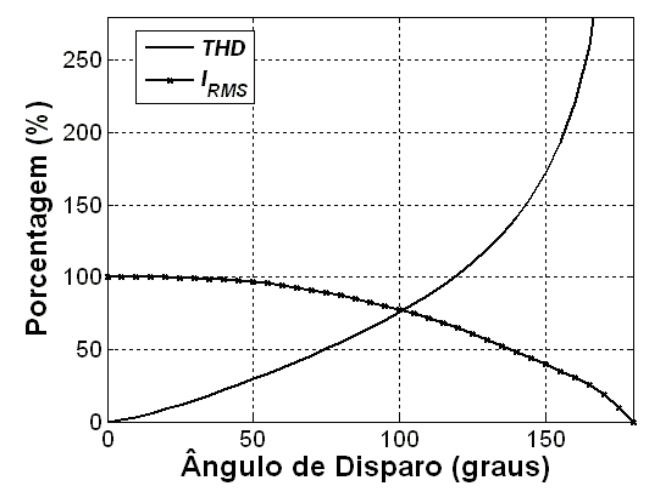

Figura 4. Variação não-linear da corrente RMS e da $T H D$.

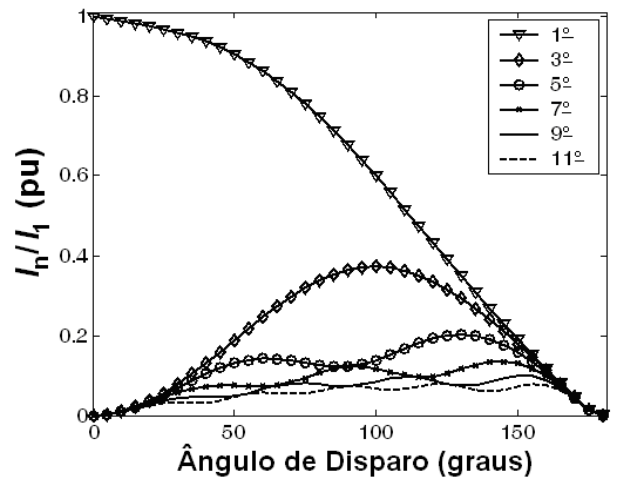

Figura 5. Amplitudes dos seis primeiros componentes.

O baixo $F P$, em conjunto com uma elevada distorção harmônica, pode causar alguns problemas como, por exemplo, a limitação da potência máxima drenada da linha de alimentação [22].

A variação das amplitudes dos seis primeiros componentes harmônicos da corrente de carga do sistema, em função do ângulo de disparo do controlador CA, é apresentada na Fig. 5. Observa-se que, acima de $150^{\circ}$, todas as amplitudes aproximam-se do valor do componente fundamental, o que eleva a distorção, mas com menor impacto no sistema em razão das suas pequenas amplitudes [4].

\section{IDENTIFICAÇÃO DO CONTEÚDO HARMÔNICO DA CORRENTE}

O diagrama esquemático para a determinação do conteúdo harmônico, usando RNA e sua aplicação num FAPP (através de um laço de realimentação), é apresentado na Fig. 6. Um conjunto de 42 amostras de amplitude do sinal de corrente é adquirido em meio ciclo da tensão da rede (amostragem de $5,04 \mathrm{kHz}$ ). Por conseguinte, uma rede neural do tipo perceptron multicamadas, composta de 42 entradas, receberá as respectivas amostras dos sinais de corrente. A estrutura do estimador neural, após ser escolhida por meio do método de validação cruzada [23], possui cinco neurônios na camada intermediária (escondida), sendo que o neurônio de saída fornece o valor do referido componente harmônico, conforme a Fig. 7. Esta estrutura neural repete-se para cada componente que se deseje determinar.

A Fig. 8 mostra o diagrama em blocos do sistema estudado. A base de dados de simulação contém 180 vetores, sendo que 90 são usados no treinamento e 90 na fase de validação. 


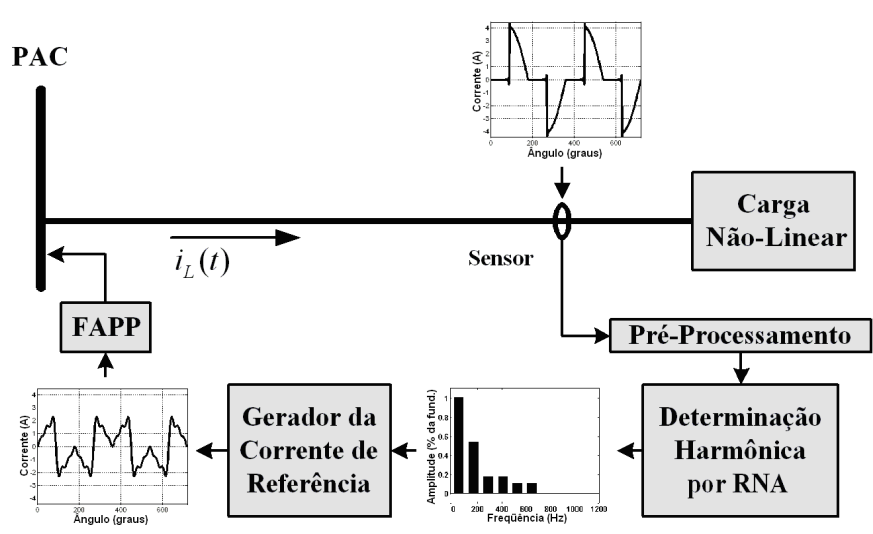

Figura 6. Processo de amostragem da corrente de carga.

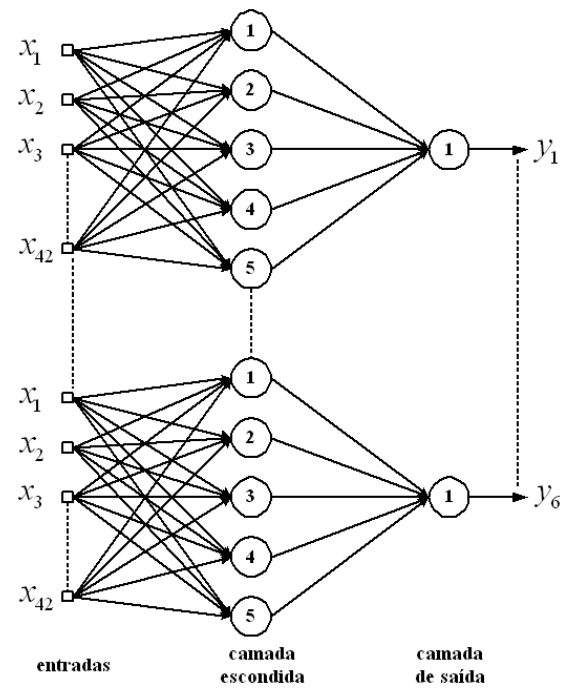

Figura 7. Arquitetura neural empregada.

Assim, a arquitetura da RNA utilizada no método proposto é, então, formada por uma rede perceptron multicamadas com treinamento supervisionado [23]. O elemento básico da rede neural é o neurônio artificial, apresentado na Fig. 9.

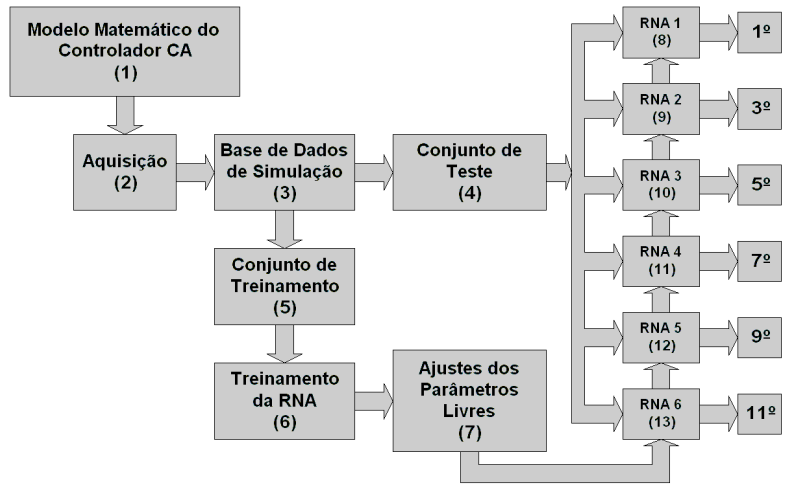

Figura 8. Diagrama de blocos do método com RNA.

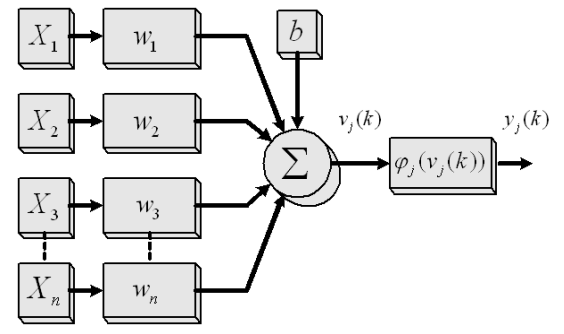

Figura 9. Representação do neurônio artificial.
O neurônio artificial, ilustrado na Fig. 9, pode ser modelado matematicamente como segue:

$$
\begin{gathered}
v_{j}(k)=\sum_{i=1}^{m} X_{i} \cdot w_{i}+b \\
y_{j}(k)=\varphi_{j}\left(v_{j}(k)\right)
\end{gathered}
$$

Onde:

$m$ é o número de sinais de entrada do neurônio;

$X_{i}$ é o $i$-ésimo sinal de entrada do neurônio;

$w_{i}$ é o peso associado com o $i$-ésimo sinal de entrada;

$b$ é o limiar de cada neurônio;

$v_{j}(k)$ é a resposta do $j$-ésimo neurônio no instante $k$;

$\varphi_{j}($.$) é a função de ativação do j$-ésimo neurônio;

$y_{j}(k)$ é o sinal de saída do j-ésimo neurônio no instante $k$.

Cada neurônio artificial, baseado nos sinais de entrada, é capaz de computar a respectiva saída por intermédio do ajuste de seus pesos. A função de ativação de cada neurônio da primeira camada escondida é a função tangente hiperbólica, enquanto a função de ativação do neurônio de saída é a função identidade. O processo de ajuste dos pesos da rede $\left(w_{j}\right)$ associados ao $j$-ésimo neurônio de saída é feito pelo cálculo do sinal de erro $e_{j}(k)$ (entre a resposta desejada e a resposta estimada) em relação à $k$-ésima iteração ou $k$-ésimo vetor de entrada. Este sinal de erro é calculado da seguinte forma:

$$
e_{j}(k)=d_{j}(k)-y_{j}(k)
$$

Onde $d_{j}(k)$ é a resposta desejada do $j$-ésimo neurônio de saída. Somando-se todos os erros quadráticos produzidos pelos neurônios de saída da rede em relação à $k$-ésima iteração, temse:

$$
E(k)=\frac{1}{2} \sum_{j=1}^{p} e_{j}^{2}(k)
$$

Onde $p$ é número de neurônios da saída. Para uma configuração de pesos ótima, $E(k)$ é minimizado por intermédio do ajuste dos pesos sinápticos $w_{j i}$. Os pesos associados à camada de saída da rede são recalculados, usando-se a seguinte expressão:

$$
w_{j i}(k)=w_{j i}(k)-\eta \frac{\partial E(k)}{\partial w_{j i}(k)}
$$

$\mathrm{O}$ peso sináptico $w_{j i}$ está conectando o $j$-ésimo neurônio da camada considerada ao $i$-ésimo neurônio da camada anterior, sendo $\eta$ a constante que determina a taxa de aprendizado do algoritmo de retropropagação. $\mathrm{O}$ ajuste dos pesos pertencentes às camadas escondidas é feito de forma análoga. Os passos para o ajuste destes pesos são detalhados em [23]. Mais especificamente, empregou-se para tanto o algoritmo de treinamento de Levenberg-Marquardt, com regularização Bayesiana, permitindo que o esforço computacional, associado ao processo de ajuste das matrizes de pesos, fosse reduzido, o que resulta na melhoria no processo de generalização da estrutura neural [24], [25]. O objetivo principal desta aplicação é obter um algoritmo que produza redes com boa generalização, restringindo o tamanho da matriz de pesos, a qual funciona como componente da regularização Bayesiana. A idéia principal é fazer com que a 
verdadeira função (a que apresenta os melhores resultados na relação entre entradas e saídas de um sistema) tenha um grau de uniformidade.

Quando os pesos em uma rede são mantidos pequenos, a resposta da mesma será uniforme. Com a regularização, qualquer rede modesta deve ser capaz de representar a função verdadeira [24]. Tipicamente, o treinamento da RNA tem por objetivo reduzir $F$, que é a soma dos erros quadráticos, representado por:

$$
F=E_{D}
$$

Sendo que:

$$
E_{D}=\sum_{i=1}^{i=n}\left(t_{i}-a_{i}\right)^{2}
$$

Onde:

$t_{i}$ é o valor desejado na saída;

$a_{i}$ é a resposta da rede;

$n$ é o número de respostas na saída.

Entretanto, na regularização adicionam-se outros termos e a função torna-se a soma dos erros quadráticos dos pesos da rede. Os termos $\gamma$ e $\lambda$ são os parâmetros daquela função. Portanto, tem-se:

$$
F=\gamma E_{D}+\lambda E_{W}
$$

Onde $E_{w}$ é a soma do quadrado dos pesos da rede. O tamanho relativo entre os parâmetros da função determina a ênfase no treinamento. Se $\gamma<<\lambda$, o algoritmo de treinamento terá erros pequenos. Se $\gamma>>\lambda$, o algoritmo reduz o tamanho dos pesos, aumentando o erro da rede e produzindo uma resposta plana na saída. A otimização Bayesiana da regularização dos parâmetros exige o cálculo da matriz Hessiana de $F(w)$ para o ponto mínimo de $w^{M P}$. A variável $w$ é o vetor dos pesos da rede e o índice $M P$ representa o ponto de mínimo do vetor de pesos. Esta proposta concentra-se no uso da aproximação de Gauss-Newton para a matriz Hessiana, a qual já está implementada no algoritmo de otimização de LevenbergMarquadt para determinação dos pontos de mínimo [24]. O esforço computacional exigido para otimizar a função de regularização é mínimo, conforme descrito no algoritmo abaixo:

1. Inicializar $\gamma, \lambda$ e os pesos. Escolhe-se inicialmente $\gamma=0$, $\lambda=1$ e usa-se o método de Nguyen-Widrow para inicializar os pesos. Após o primeiro passo de treinamento, os parâmetros da função retornam aos valores originais;

2. Usa-se o algoritmo de Levenber-Marquadt para minimizar a função $F=\lambda E_{D}+\gamma E_{W}$;

3. Calcula-se o número efetivo de parâmetros usando a aproximação de Gauss-Newton na matriz Hessiana do algoritmo de Levenberg-Marquadt;

4. Calcula-se o valor de $\gamma$ e $\lambda$;

5. Retorna o algoritmo ao passo 2 , indo até 4 , enquanto não convergir os valores de $\gamma$ e $\lambda$.

Assim, baseada na metodologia proposta, a corrente instantânea amostrada do controlador CA é apresentada à
RNA, que estima um componente harmônico específico presente nesta corrente.

As Figs. 10 a 15 ilustram os resultados da estimativa do conteúdo harmônico das RNA, assim como apresentam o valor desejado. Os resultados de generalização fornecidos pela estrutura neural são obtidos através do cômputo de operações matriciais elementares com matrizes de pesos de pequenas dimensões, o que reduz o custo computacional em relação a outras metodologias [7], [8], [13], [14].

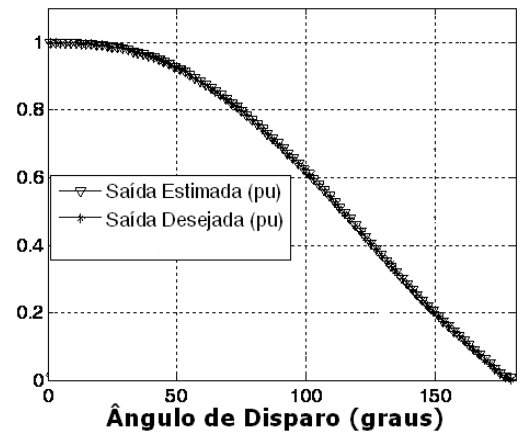

Figura 10. Estimativa do componente fundamental.

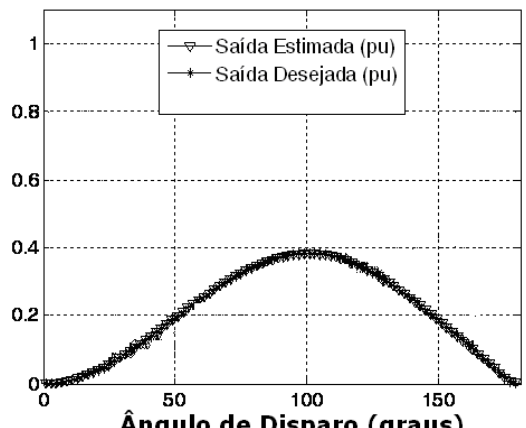

Figura 11. Estimativa do 3 oㅡ conteúdo harmônico.

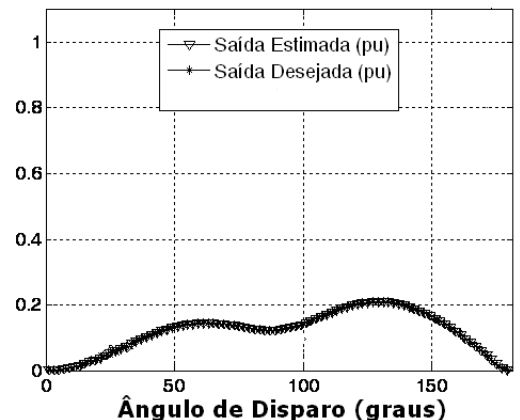

Figura 12. Estimativa do $5^{\circ}$ conteúdo harmônico.

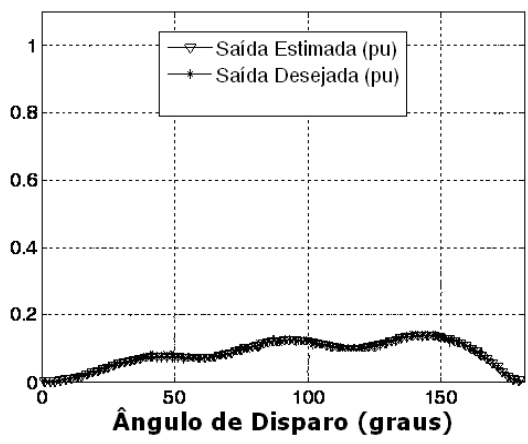

Figura 13. Estimativa do $7^{\circ}$ conteúdo harmônico. 


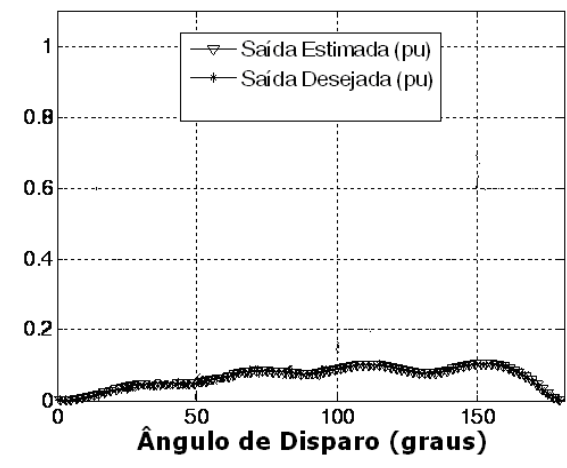

Figura 14. Estimativa do $9^{\circ}$ conteúdo harmônico.

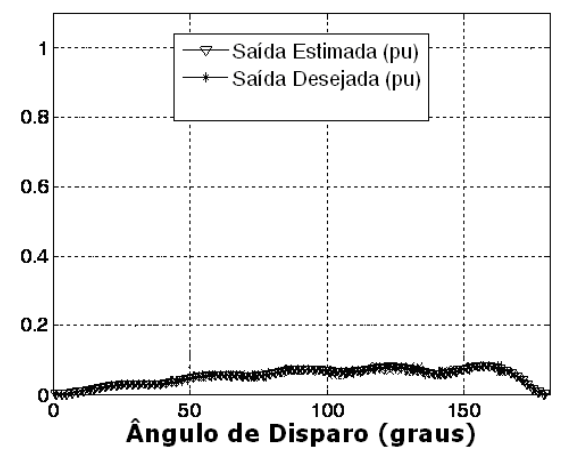

Figura 15. Estimativa do $11^{\circ}$ conteúdo harmônico.

Em todos os harmônicos estimados, o erro relativo ficou abaixo de $1 \%$ na faixa entre $25^{\circ}$ e $160^{\circ}$. A única exceção é para o componente fundamental, ilustrado por meio da Fig. 10 , onde o erro ficou abaixo de $0,2 \%$ até aproximadamente $140^{\circ}$ e acima de $1 \%$ após $160^{\circ}$.

$\mathrm{O}$ erro de generalização para ângulos de disparo abaixo de $10^{\circ}$ (exceto para o componente fundamental mostrado na Fig. 10) e acima de $160^{\circ}$ foi da ordem de $10 \%$, ilustrados nas Figs. 10 a 15. Este erro caracteriza uma limitação à aplicação da metodologia proposta neste trabalho. Entretanto, devido à baixa amplitude dos componentes harmônicos nestas regiões de operação do controlador CA, as mesmas podem ser ignoradas para aplicações em situações práticas.

\section{IDENTIFICAÇÃO HARMÔNICA USANDO A FFT TRUNCADA}

A determinação do conteúdo harmônico de um sistema monofásico é de fundamental importância para o cálculo das perdas no sistema de distribuição de energia elétrica, dimensionamento das redes, e em aplicações de correção ativa de distorção harmônica. Um dos métodos tradicionalmente encontrado na literatura é a FFT [14]. Neste artigo, os resultados da determinação harmônica que usa a RNA são comparados com a FFT.

Os harmônicos do controlador CA são determinados valendo-se do algoritmo da FFT truncada no sexto harmônico (online). Este método apresenta um resultado satisfatório, porém o esforço computacional é maior do que o método usando RNA. A diferença de esforço computacional pode ser verificada a partir do tempo de processamento observado após a RNA ter sido treinada, pois, neste caso, o tempo de obtenção de uma resposta pela RNA é $24,96 \%$ mais rápido do que o da FFT truncada, que utiliza a mesma plataforma computacional.
Assim, é realizada a comparação entre o método de estimativa dos seis primeiros componentes por meio da RNA e do método que usa o algoritmo da FFT truncada no sexto componente harmônico através da corrente RMS. Em ambos os casos, as amplitudes resultantes são aplicadas em (7) para o cálculo desta corrente. A Fig. 16 ilustra, na forma de um diagrama em blocos, como foi calculada a corrente RMS para os componentes estimados por um conjunto de RNA e também aqueles determinados pela FFT truncada.

Os resultados comparativos entre as duas metodologias são apresentados na Tabela I, na qual o erro relativo para cada linha da tabela é calculado em relação aos resultados de (6).

A Tabela I apresenta a corrente RMS gerada com base nos componentes estimados por um conjunto de RNA e a corrente RMS gerada, valendo-se dos componentes harmônicos obtidos pela FFT truncada no sexto componente. $\mathrm{O}$ erro relativo manteve-se abaixo de $1 \%$, até aproximadamente o ângulo de disparo de $130^{\circ}$.

Observa-se que na principal faixa de interesse para este tipo de carga (para os ângulos de disparo do controlador CA entre $50^{\circ}$ e $150^{\circ}$ ), o método proposto apresenta menor erro relativo quando comparado à FFT truncada na estimativa das amplitudes dos harmônicos da corrente RMS estimada e calculada, conforme ilustrado na Tabela I.

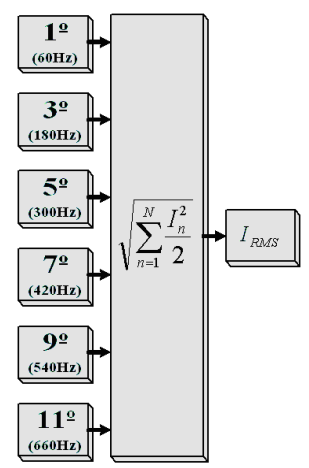

Figura 16. Método usado para gerar a corrente RMS.

TABELA I

RESULTADOS USANDO RNA E FFT TRUNCADA

\begin{tabular}{|c|c|c|c|c|c|}
\hline \multirow{2}{*}{$\boldsymbol{\alpha}$} & \multicolumn{3}{|c|}{ Corrente RMS } & \multicolumn{2}{c|}{ Erro Relativo } \\
\cline { 2 - 6 } (graus) & $\begin{array}{c}\text { Teórica } \\
(\mathbf{p u})\end{array}$ & $\begin{array}{c}\text { FFT } \\
(\mathbf{p u})\end{array}$ & $\begin{array}{c}\text { RNA } \\
\mathbf{( p u )}\end{array}$ & $\begin{array}{c}\text { FFT } \\
\mathbf{( \% )}\end{array}$ & $\begin{array}{c}\text { RNA } \\
\mathbf{( \% )}\end{array}$ \\
\hline 0 & 1,0000 & 1,0000 & 1,0000 & 0 & 0 \\
\hline 10 & 0,9997 & 0,9994 & 0,9996 & 0,0300 & 0,0100 \\
\hline 20 & 0,9978 & 0,9967 & 0,9975 & 0,1102 & 0,0301 \\
\hline 30 & 0,9926 & 0,9904 & 0,9919 & 0,2216 & 0,0705 \\
\hline 40 & 0,9826 & 0,9789 & 0,9816 & 0,3766 & 0,1018 \\
\hline 50 & 0,9665 & 0,9610 & 0,9649 & 0,5691 & 0,1655 \\
\hline 60 & 0,9431 & 0,9358 & 0,9409 & 0,7740 & 0,2333 \\
\hline 70 & 0,9121 & 0,9024 & 0,9092 & 1,0635 & 0,3179 \\
\hline 80 & 0,8737 & 0,8617 & 0,8702 & 1,3735 & 0,4006 \\
\hline 90 & 0,8284 & 0,8144 & 0,8242 & 1,6900 & 0,5070 \\
\hline 100 & 0,7760 & 0,7593 & 0,7711 & 2,1521 & 0,6314 \\
\hline 110 & 0,7155 & 0,6964 & 0,7099 & 2,6695 & 0,7827 \\
\hline 120 & 0,6458 & 0,6248 & 0,6395 & 3,2518 & 0,9755 \\
\hline 130 & 0,5671 & 0,5429 & 0,5601 & 4,2673 & 1,2344 \\
\hline 140 & 0,4825 & 0,4554 & 0,4747 & 5,6166 & 1,6166 \\
\hline 150 & 0,3957 & 0,3665 & 0,3868 & 7,3793 & 2,2492 \\
\hline 160 & 0,3050 & 0,2642 & 0,2945 & 13,377 & 3,4426 \\
\hline 170 & 0,1872 & 0,1274 & 0,1743 & 31,944 & 6,8910 \\
\hline
\end{tabular}




\section{APLICAÇÃO DOS RESULTADOS DA IDENTIFICAÇ̃̃o HARMÔNICA}

Os principais resultados de simulação da aplicação envolvendo o conteúdo harmônico estimado pela RNA, o controlador CA e o FAPP, são descritos nesta seção. A simulação foi realizada com a ferramenta computacional Matlab/Simulink. A Fig. 1 mostra o diagrama do sistema simulado, o qual é formado por uma fonte de tensão senoidal $(60 \mathrm{~Hz})$, por um conversor CC-CA de tensão monofásico $\mathrm{PWM}$, em ponte completa, conectado ao PAC, e por um controlador CA.

Com base no conteúdo harmônico da corrente de carga $\left(i_{L}(t)\right)$, calcula-se a corrente de compensação harmônica $\left(i_{f}(t)\right)$ expressa em (21). No domínio do tempo, a corrente de carga é medida e amostrada; logo após, as amplitudes contidas em meio ciclo da forma de onda da tensão da rede são fornecidas para a RNA. Com o sinal normalizado, a RNA estima a amplitude dos seis primeiros componentes harmônicos. A partir destes resultados, é gerada a corrente de referência no domínio de tempo que é usado pelo sistema de controle do FAPP para a compensação harmônica. A corrente da fonte de alimentação $\left(i_{s}(t)\right)$, portanto, fornece o componente fundamental mais os harmônicos que não são compensados (a partir do $13^{\circ}$ ), é representada em (22).

$$
\begin{gathered}
i_{f}(t)=\sum_{n=3}^{11} I_{n} \operatorname{sen}\left(n \omega t+\theta_{n}\right) \\
i_{S}(t)=I_{1} \operatorname{sen}\left(\omega t+\theta_{1}\right)+\sum_{n=13}^{\infty} I_{n} \operatorname{sen}\left(n \omega t+\theta_{n}\right)
\end{gathered}
$$

A Fig. 17 ilustra o comportamento da THD antes e após a compensação harmônica, demonstrando, dessa forma, a eficácia do FAPP proposto.

Os resultados obtidos demonstram que a técnica empregada na determinação dos componentes harmônicos, em conjunto com o FAPP proposto, é capaz de atenuar consideravelmente os harmônicos do sistema por meio do cancelamento de parte da distorção harmônica vista pelo PAC. A Fig. 18 mostra a corrente da fonte $\left(i_{s}(t)\right)$ no PAC, antes e após o início de operação do FAPP (início do segundo ciclo da forma de onda da tensão da rede) e a corrente de carga $\left(i_{L}(t)\right) \operatorname{com} \alpha=90^{\circ}$. A corrente corrigida ainda não tem uma forma de onda senoidal pura, mas o THD sofreu uma considerável redução de $64,71 \%$ para 20,77\%, ilustrada na Fig. 17. O FP também melhorou, pois passou de 0,7082 para 0,8259 .

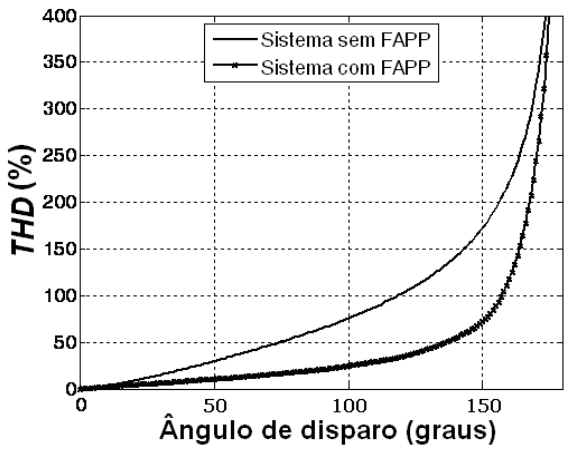

Figura 17. THD antes e após a compensação harmônica.
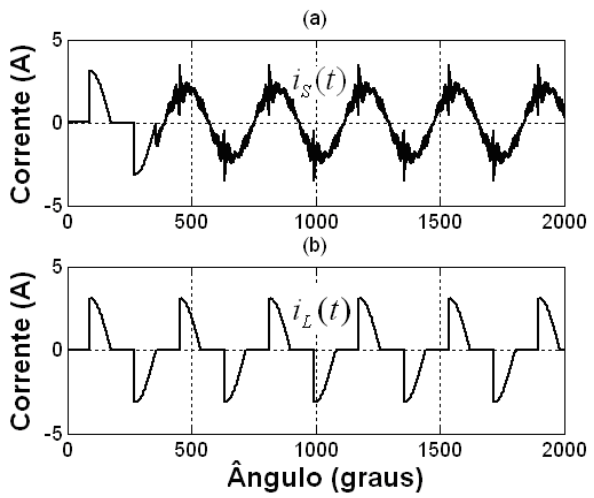

Figura 18. (a) Corrente compensada $i_{s}(t)$; (b) corrente de carga $i_{L}(t)$.

$\mathrm{O}$ método proposto também se mostra eficaz e robusto quando existem mudanças na corrente de carga. A Fig. 19 apresenta o resultado para a mudança do ângulo de disparo de $90^{\circ}$ para $60^{\circ}$. Inicialmente, o ângulo de disparo é ajustado para $90^{\circ}$. Em $\omega t=\omega t_{1}$, o FAPP começa a compensação, apresentando os mesmos resultados da Fig. 18. Em seguida, em $\omega t=\omega t_{2}$, o ângulo de disparo é mudado para $60^{\circ}$, gerando transitórios maiores na corrente drenada da fonte $\left(i_{s}(t)\right)$. Após um ciclo em $\omega t=\omega_{3}$ o filtro começa a compensação para $\alpha=$ $60^{\circ}$. A Fig. 20 mostra o resultado para a mudança de amplitude $\left(\alpha=90^{\circ}\right)$. Em $\omega t=\omega t_{2}$, ocorre a queima de uma lâmpada. Logo após, em $\omega t=\omega_{3}$, o FAPP inicia a compensação para a corrente drenada por duas lâmpadas.
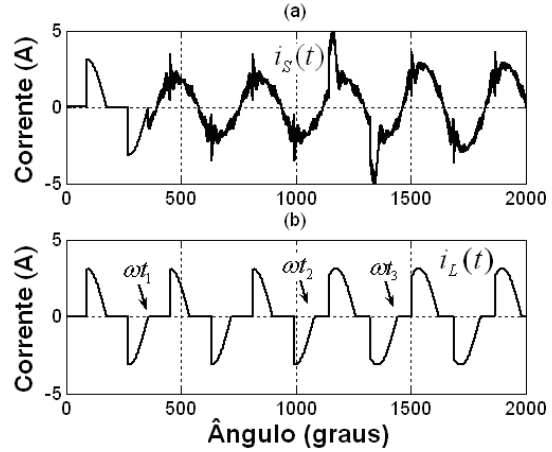

Figura 19. (a) Corrente compensada $i_{s}(t)$; (b) corrente de carga $i_{L}(t)$.
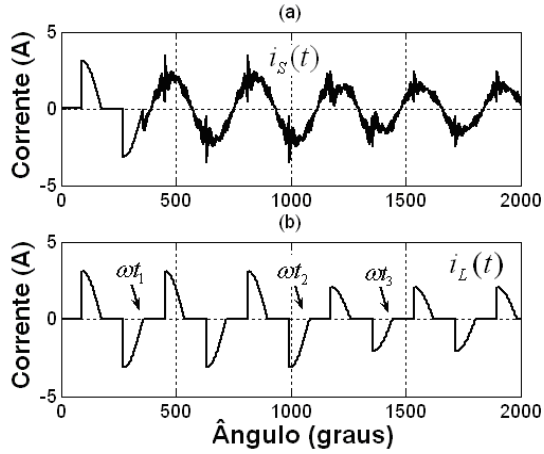

Figura 20. (a) Corrente compensada $i_{s}(t)$; (b) corrente de carga $i_{L}(t)$.

\section{CONCLUSÕES}

Neste trabalho, apresentou-se um método alternativo na determinação do conteúdo harmônico em uma rede monofásica com uma carga não-linear e variante no tempo baseado em redes neurais artificiais. O controlador CA, 
funcionando como dimmer, tem um comportamento harmônico variável, pois as amplitudes de cada componente harmônico dependem do ângulo de disparo e da variação da resistência das lâmpadas com a temperatura.

A RNA mostrou-se como uma solução eficaz na determinação dos componentes harmônicos (no domínio do tempo), mesmo sob as variações na forma de onda de corrente causadas pelo dimmer. A metodologia proposta, quando comparada a FFT, estima o conteúdo harmônico de uma rede CA monofásica com menor esforço computacional e menor erro relativo na faixa do ângulo de disparo de $10^{\circ}$ a $160^{\circ}$.

Os métodos convencionais para a determinação dos harmônicos podem apresentar certas limitações, tais como o esforço computacional elevado em razão da necessidade de multiplicações complexas, a freqüência de amostragem ser maior que o dobro da freqüência do sinal amostrado e o número de pontos amostrados serem potência de dois. Por outro lado, a RNA proposta não possui estas limitações, pois analisa a amplitude do sinal no tempo e em meio ciclo.

A estimativa dos componentes harmônicos de corrente demonstra a capacidade de uma RNA em aprender os padrões e estabelecer a correlação entre a amplitude da forma de onda e o conteúdo harmônico do sinal, além de mapear as entradas em função da saída de um sinal que varia no tempo. A melhor relação entre custo computacional e resultados de generalização foi encontrada com o uso de 5 neurônios na primeira camada escondida, empregando-se a função de ativação tangente hiperbólica.

Os resultados obtidos com a RNA podem ser aplicados a um FAPP simulado, tanto para a compensação dos harmônicos de corrente como para a correção da potência reativa fundamental, pois há o acesso a cada amplitude dos componentes harmônicos, inclusive do componente fundamental da fonte de alimentação CA.

Em suma, o método baseado em RNA mostrou-se capaz de determinar o conteúdo harmônico de uma rede monofásica CA ligada a uma carga não-linear e variante no tempo em apenas um semiciclo da tensão de alimentação CA.

\section{AgRAdECIMENTOS}

Os autores reconhecem as contribuições da Professora Dra. Marilu Martens de Oliveira.

\section{REFERÊNCIAS}

[1] J. Stones, and A. Collinson, "Power quality," Power Engineering Journal, vol. 15 , no. 2, pp. 58-64, 2001

[2] F. P. Marafão, S. M. Deckmann, and H. K. Morales, "A influência da referência de tensão na avaliação de indicadores de qualidade de energia," IEEE Latin America Transactions, v6, n.1, pp. 81-87, 2008.

[3] L. A. Morán, J. W. Dixon, J. R. Espinoza, and R. R. Wallace, "Using Active Power Filters to Improve Power Quality," in Proc. of COBEP'99, pp. 501-511, 1999.

[4] C. F. Nascimento, "Determinação do conteúdo harmônico de corrente baseada em redes neurais artificiais para cargas não-lineares monofásicas," Tese de Doutorado, EESC, Universidade de São Paulo, São Carlos, SP, Brasil, 2007.

[5] H. Akagi, "Active harmonic filters," in Proc. of the IEEE, vol. 93, no. 12, pp. 2128-2141, 2005.

[6] H. Akagi, E.H. Watanabe, and M.Aredes, Instantaneous Power Theory and Applications to Power Conditioning, John Wiley, NJ, 2007.
[7] S. Mariethoz, and A. C. Rufer, "Open loop and closed loop spectral frequency active filtering," IEEE Transactions on Power Electronics, vol. 17, no. 4, pp. 564-673, 2002.

[8] M. El-Habrouk, and M. K. Darwish, "Design and implementation of modified fourier analysis harmonic current computation technique for power active filters using DSPs," IEE Proceedings Electric Power Applications, vol. 148, no. 1, pp. 21-28, 2001.

[9] A. A. Oliveira Jr, C. F. Nascimento, E. C. C. Cichy, J. R. B. A. Monteiro, and M. L. Aguiar, "Introducing the learning of active power filters using the software matlab-simulink," in Proc. of PESC/PEEW 2005, pp. 108-113, 2005.

[10] L. P. Kunjumuhammed, and M. K. Mishra, "A control algorithm for single-phase active power filter under non-stiff voltage source," IEEE Transactions on Power Electronics, vol. 21, no. 3, pp. 822-825, 2006.

[11] L. S. Czarnecki, "Instantaneous reactive power p-q theory and power properties of three-phase systems," IEEE Transactions on Power Delivery, vol. 21, no. 1, pp. 362-367, 2006.

[12] M. Kale, and E. Özdemir, "Harmonic and reactive power compensation with shunt active power filter under non-ideal mains voltage," Electric Power Systems Research, vol. 74, no. 3, pp. 363-370, 2005.

[13] M. Wang, and Y. Sun, "A practical method to improve phasor and power measurement accuracy of DFT algorithm," IEEE Transactions on Power Delivery, vol. 21, no. 3, pp. 1054-1062, 2006.

[14] J. G. Proakis, and D. G. Manolakis, Digital Signal Processing: principles, algorithms, and applications, 3rd ed., Prentice Hall, 1996.

[15] S. A. Souza, R. A. Macedo, E. T. Vargas, D. V. Coury, and M. Oleskovicz, "Estimação de parâmetros de um sistema elétrico de potência utilizando algoritmos genéticos," IEEE Latin America Transactions, vol. 4, no. 1, pp. 47-54, 2006.

[16] D. O. Abdeslam, P. Wira, J. Merckle, D. Flieller, and Y.-A. Chapuis, "A unified artificial neural network architecture for active power filters," IEEE Transactions on Industrial Electronics, vol. 54, no.1, pp. 61-76, Feb. 2007.

[17] C. Madtharad, and S. Premrudeepreechacharn, "Active power filter for three-phase four-wire electric systems using neural networks," Electric Power Systems Research, no. 60, pp. 179-192, 2002.

[18] M. Rukonuzzaman, and M. Nakaoka, "Single-phase shunt active power filter with harmonic detection," IEE Proceedings Electric Power Applications, vol. 149, no. 5, pp. 343-350, 2002.

[19] L. H. Tey, P.L. So, and Y. C. Chu, "Adaptive neural network control of active filters," Electric Power Systems Research, no. 74, pp. 37-56, 2005

[20] J. R. Vazquez, and P. Salmeron, "Active power filter control using neural network technologies," IEE Proc. Electr. Power Appl., vol. 150, no. 2 , pp. 139-145, 2003.

[21] F. J. Alcantara, and P. Salmeron, "A new technique for unbalance current and voltage estimation with neural networks," IEEE Transactions on Power Systems, vol. 20, no. 2, pp. 852-858, 2005.

[22] R. W. Erickson, Fundamentals of Power Electronics, Chapman \& Hall, 1997.

[23] S. Haykin, Neural Networks, 2nd edition, Prentice Hall, 1999

[24] M. T. Hagan, and M. B. Menhaj, "Training feedforward networks with the Marquardt algorithm," IEEE Transactions on Neural Networks, vol. 5, no. 6, pp. 989-993, 1994.

[25] F. D. Foresee, and M. T. Hagan, "Gauss-Newton approximation to Bayesian learning," in Proc. of International Conference on Neural Networks, vol. 3, pp. 1930-1935, 1997.

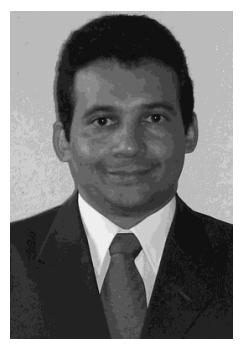

Claudionor Francisco do Nascimento, nascido em 08/11/1966 em Bauru (SP) é engenheiro eletricista (1991) pela Universidade Estadual Paulista (UNESPFEB); mestre (2003) e doutor em Engenharia Elétrica (2007) pela Escola de Engenharia de São Carlos (EESC) da Universidade de São Paulo (USP). Atualmente é professor do CECS da Universidade Federal do ABC (UFABC) desde 2009. Suas áreas de interesse são: eletrônica de potência, qualidade da energia elétrica, harmônicos em sistemas elétricos de potência, sistemas inteligentes, acionamentos de máquinas elétricas e ensino de Engenharia Elétrica. É membro da SOBRAEP. 


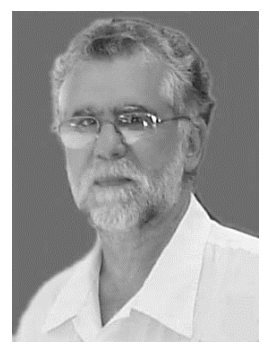

Azauri Albano de Oliveira Júnior, nascido em 23/07/1955 em Franca (SP) é engenheiro eletricista/eletrônico (1977) pela Escola de Engenharia de São Carlos (EESC) da Universidade de São Paulo (USP); mestre em Engenharia Elétrica (1984) pela EESC-USP e doutor em Engenharia Elétrica (1991) pela Escola Politécnica da USP. É coordenador do Laboratório de Controle e Eletrônica de Potência (LACEP) do Departamento de Engenharia Elétrica da EESC-USP. É coordenador da Comissão Coordenadora do Curso de Engenharia Elétrica da EESC-USP. É professor do Departamento de Engenharia Elétrica da EESC-USP desde 1977. Suas áreas de interesse são: eletrônica de potência, acionamento e controle de máquinas elétricas e ensino de Engenharia Elétrica. É membro da ABENGE e da SOBRAEP.

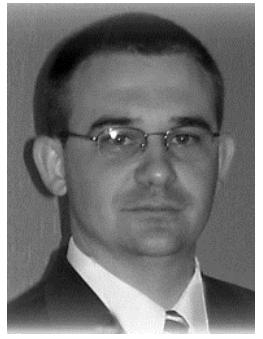

Alessandro Goedtel, nascido em 12/02/1972 em Arroio do Meio (RS) é engenheiro eletricista (1996) pela Universidade Federal do Rio Grande do Sul (UFRGS-DEE); mestre em Engenharia Industrial (2003) pela Universidade Estadual Paulista (UNESPFEB) e doutor em Engenharia Elétrica (2007) pela Escola de Engenharia de São Carlos (EESC) da Universidade de São Paulo (USP). É professor do Departamento de Eletrotécnica da Universidade Tecnológica Federal do Paraná (UTFPR-CP) desde 2007. Suas áreas de interesse são: acionamento de máquinas, sistemas inteligentes e ensino de Engenharia Elétrica. É membro da SBA.

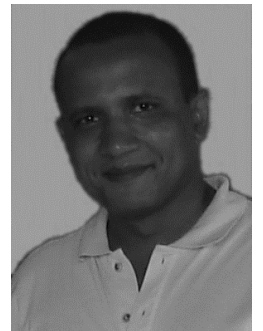

Ivan Nunes da Silva, nascido em 03/08/1967 em São José do Rio Preto (SP) é engenheiro eletricista (1992) e bacharel em ciência da computação (1991) pela Universidade Federal de Uberlândia; mestre (1995) e doutor em Engenharia Elétrica (1997) pela Universidade Estadual de Campinas (UNICAMP). É coordenador do Laboratório de Automação Inteligente de Processos e Sistemas (LAIPS). É professor associado do Departamento de Engenharia Elétrica da Escola de Engenharia de São Carlos (EESC) da Universidade de São Paulo (USP) desde 2004. Suas áreas de interesse são: sistemas inteligentes, identificação de processos e Ensino de Engenharia. É membro da SBA e IEEE, sendo atualmente editor associado da revista Controle \& Automação.

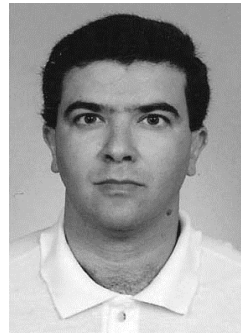

Paulo José Amaral Serni, nascido em 30/03/1957 em Botucatu (SP) é engenheiro eletricista (1987) pela Faculdade de Engenharia e Tecnologia; mestre (1992) e doutor em Engenharia Elétrica (1999) pela Universidade Estadual de Campinas (UNICAMP). É professor do Departamento de Engenharia Elétrica da Universidade Estadual Paulista (UNESP-FEB) desde 1987. Suas áreas de interesse são: acionamento de máquinas, sistemas inteligentes, qualidade da energia elétrica, harmônicos em sistemas elétricos de potência, eletrônica de potência e ensino de Engenharia Elétrica. É membro da SOBRAEP. 